\title{
Research on the Restrictive Factors of Transformation and Upgrading in Yunnan Manufacturing Industry
}

\author{
Meijuan $\mathrm{Li}^{\mathrm{a}}$, Duo Yan

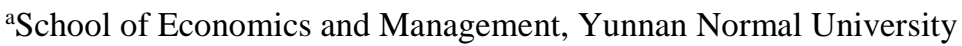 \\ Kunming and 650500, China \\ ${ }^{\mathrm{b}} \mathrm{School}$ of Economics and Management, Yunnan Normal University \\ Kunming and 650500, China
}

\begin{abstract}
With the rapid development of economy, Yunnan is facing great challenges in the economic status from the whole country, the transformation and upgrading of its manufacturing industry are imminent. This paper focuses on the analysis of the main restrictive factors of transformation and upgrading in Yunnan manufacturing industry, and puts forward the corresponding countermeasures. The research shows that the main restrictive factors of transformation and upgrading in Yunnan manufacturing industry are the traditional path dependence, insufficient professional talents reserve, inadequate financial assistance, incomplete logistics system, weak independent innovation. Accordingly, the countermeasures proposed mainly include, promoting the transformation of the manufacturing structure from singleness to diversification, accelerating the implementation of manufacturing cluster development strategy, establishing cooperative mechanism in universities, increasing financial support, balancing the allocation of industrial financial resources, increasing the construction of logistics infrastructure, and actively exploring new technological innovation models.
\end{abstract}

Keywords-Manufacturing; Transformation and upgrading; Restrictive factors

\section{INTRODUCTION}

As a big manufacturing country, China has faced fierce global competition since joining the WTO. The transformation and upgrading of manufacturing industry in China has been accelerating. At the same time, the process of industrialization and urbanization in China has not yet been completed, which has caused certain difficulties for the transformation of China's economy. In the real economic life, although China's manufacturing industry is continuously rising in number, the use of demographic dividends and relatively low-cost labor costs make the manufacturing industry occupy a larger portion of the national economy. However, with the increase of labor cost in China in recent years, the competitiveness of China's manufacturing industry has declined, and there is a big gap between China's manufacturing industry and developed countries [1]. Therefore, it is imperative to rely on scientific and technological progress to promote the upgrading of China's manufacturing industry. For Yunnan Province, due to the constraints of Yunnan's unique geography and natural environment, the natural economy is less developed. At present, the economic development of Yunnan is relatively slow, and the level of economic development and manufacturing have obviously lagged behind the developed coastal areas in the east. In addition, there are many unfavorable influencing factors in the process of industrial transformation and upgrading, which seriously restricts the transformation and upgrading of industries in Yunnan Province. Therefore, the study of the restrictive factors of transformation and upgrading in Yunnan Manufacturing Industry is a necessary prerequisite for the industrial transformation and upgrading of Yunnan Province.

Under the global competition environment where the current value chain is closely integrated and the technological innovation boom continues, how does Yunnan make use of its regional advantages and industrial advantages to smoothly undertake the transfer of manufacturing industries from east to west, and complete the industrial upgrading of manufacturing industry in Yunnan? Which is very important significance. We start with the factors that restrict the transformation and upgrading of the manufacturing industry in Yunnan Province, put forward corresponding suggestions, which is positive significance to improve the economic situation in Yunnan Province.

\section{DEVELOPMENT STATUS OF YUNNAN'S MANUFACTURING INDUSTRY}

\section{A. The rapid development of industrial enterprises and the remarkable economic benefits of the manufacturing industry}

In the initial stage of China's economic development, the importance of manufacturing to the economic development of a province is self-evident [2]. In recent years, with the advancement of the Western Development Policy and the One Belt and One Road Policy, the industry in Yunnan Province has developed rapidly. In the end of 2017, the realized added value of the above-scale industries in the province was 337.84 billion yuan, a year-on-year increase of $9.5 \%, 4.1$ percentage points higher than the same period of 2016 , and 2.9 percentage points higher than the national $6.6 \%$. In 2017, the added value of the secondary industry was 638.753 billion yuan, an increase of $10.7 \%$, and the growth rate was 4.6 percentage points higher than the national average. This shows that Yunnan's industrial enterprises have been greatly improved in 
both quantity and scale, laid the foundation for the continuous increase in manufacturing production. Although the overall economic strength of Yunnan Province is low, the pace of industrial development is still relatively fast, which is higher than the development speed of national industrial scale. However, the quality of Yunnan's manufacturing industry is still worthy of discussion.

In 2016, Yunnan's manufacturing industry increased by $8.5 \%$, an increase of 2.9 percentage points over the same period of 2015, stimulated growth with industries above scale by 6.2 percentage points. In 2017, the nine major traditional manufacturing industries in Yunnan Province have achieved growth, including traditional manufacturing industries, such as non-ferrous metal smelting and rolling processing and nonmetallic mineral products industries. These have aggregated annual industrial growth of over 20 million yuan in Yunnan's main business income. The contribution rate was $29.3 \%$, which pulls a growth of $3.2 \%$. It can be seen that the largescale development of the manufacturing industry in Yunnan Province has brought about certain economic benefits, which has spurred the province's economic development level.

\section{B. There is a big gap between Yunnan and other developed provinces and cities with regard to comprehensive competitiveness}

Although Yunnan's manufacturing industry has made significant progress in structural optimization and industrial upgrading, there are issues, such as the relatively low industry level, relatively slow industrial upgrading speed, and relatively low per capita added value [3]. Compared with developed provinces and cities, such as Jiangsu, Zhejiang, Guangdong, and Shandong, where the level of economic development is better, the overall competitiveness of manufacturing industry in Yunnan is not too high.

In 2017, the proportions of high-tech intensive manufacturing industries in Zhejiang, Guangdong, and other developed provinces and cities have reached more than $80 \%$. It can be seen that the manufacturing developments of these coastal provinces and cities mainly depend on scientific and technological innovation and technological progress, while Yunnan Province is only $12.76 \%$.It can be seen that the technology level of Yunnan's manufacturing is relatively insufficient, and the lack of high technology leads to the development of the manufacturing industry mostly based on low-tech labor-intensive types. Compared with the average level of the development of national manufacturing industry, the average development level of the nation's technologyintensive manufacturing industry in 2017 was $52.13 \%$, but Yunnan is only $12.76 \%$. It can be seen that there is a big gap in the development level of the manufacturing industry between Yunnan and the national average. Science and technology are the primary productive forces, there are major obstacles to the development of the manufacturing industry in Yunnan, where the technology is inherently inadequate.
The adjustment of industrial structure tends to optimization, the new industrialization system is being constructed

During the "Twelfth Five-Year Plan" period, the aim of adjustment of the industrial structure in Yunnan Province is to build a new type of industrialization system, combine government guidance with the allocation of market mechanisms, vigorously develop light industry, optimize and upgrade heavy industry, and accelerate the cultivation of new industries. As we all know, Yunnan's tobacco manufacturing industry has always occupied an important proportion of the economy, but fortunately, the proportion of tobacco manufacturing industry in Yunnan Province has gradually decreased in recent years. In 2017, the province's tobacco product decreased by $1.9 \%$. At the same time, the ferrous metal smelting and rolling processing industry increased by $9.02 \%$, the nonferrous metal smelting and rolling processing industry increased by $6.94 \%$, the coal mining and washing industry increased by $7.63 \%$, and the nonmetal mineral products industry increased by $14.96 \%$. Therefore, since the "Twelfth Five-Year Plan" period, the industrial structure of Yunnan Province has changed the deformed development of the unhealthy industry which used to rely solely on tobacco. The focus of the manufacturing industry has gradually shifted from tobacco to other industries. Through the integration of resources with emerging industries, such as iron and steel, non-ferrous metals, metallurgy, phosphorus chemicals, and equipment manufacturing, the structure of the manufacturing industry in Yunnan Province has become more rationalized, and the efficiency of resource use has continued to increase, and new industrial systems have begun to gradually form.

\section{THE RESTRICTIVE FACTORS OF TRANSFORMATION AND UPGRADING IN YUNNAN MANUFACTURING INDUSTRY}

\section{A. Traditional path dependence}

In Yunnan Province, there are many cities with developed manufacturing industries, but most of these cities are resourcebased cities, such as Dongchuan, Gejiu, Maguan and Yuxi, where rely on traditional resource advantages for development. In recent years, with the gradual lack of resources, it has still not changed the traditional path and still relies on traditional resource advantages to create regional GDP. At the same time, Yunnan's manufacturing industry mainly relies on resources such as metallurgy, tobacco, coal and labor-intensive industries, there are few technological and capital-intensive manufacturing companies. Therefore, Yunnan's manufacturing structure heavily relies on traditional resource-based industries, with a single development path, no corresponding innovations, no complete development of related subsidiary industries and related service industries. With the gradual lack of resources, many manufacturing industries in the city will face a huge development crisis. 


\section{B. Insufficient professional talents reserve}

One of the main reasons for the stagnation of the manufacturing industry in Yunnan is the shortage of professional talents [4]. Professional and technical personnel are the prerequisite for promoting the development of the manufacturing industry. Compared with Zhejiang and Jiangsu, where there are more than $70 \%$ of manufacturing professionals and higher education professionals, Yunnan Province lags far behind and is only about $24.57 \%$. It can be seen that there is a huge gap between Yunnan and developed provinces in manufacturing professionals. The reason is mainly because the Yunnan's higher education and development of manufacturing industry is not very close, and there is no corresponding reserve of professional talents. Secondly, the expansion of the enrollment scale of higher education institutions in Yunnan Province does not align well with the professional subdivision talents needed for the development of the manufacturing industry, which makes the manufacturing industry in Yunnan lack a corresponding technical foundation. In addition, there are few related schools and vocational colleges for the cultivation of specialized manufacturing talents in Yunnan Province, the proportion of higher education talents who enter into the high-tech manufacturing industry is declining year by year.

\section{Inadequate financial assistance}

For the manufacturing industry, the financial assistance is very important. To achieve development, the manufacturing industry must continuously expand the scale of development and upgrade the technological level. Among them, the financial institutions plays an important role. The financial institutions are the most important funding source for the development and growth of manufacturing industries. However, in the process of manufacturing development in Yunnan Province, the financial institutions do not have very good support, and financial services have a lot of problems. According to the corresponding data, the number of financial institutions in Yunnan Province in 2017 was only about 1,213, which is very low compared to more than 8,000 in Jiangsu. Secondly, in 2017, the major financial institutions in Yunnan Province invested 2.544 trillion yuan in the secondary industry, which was a $1.9 \%$ decrease from the same period of 2016, of which manufacturing investment was approximately 187.623 billion yuan. This data has a big gap compared to the developed provinces. For example, in 2017, the investment of the second industry in Jiangsu Province had reached more than 23,000 billion yuan, of which manufacturing investment accounted for more than $75 \%$ of the investment in the second industry, which was about 10 times of the manufacturing industry in Yunnan Province. Therefore, it can be seen that the relevant financial institutions in Yunnan Province are not enough to support the manufacturing industry.

\section{Incomplete logistics system}

The rapid development of manufacturing industry is inseparable from the corresponding rapid logistics services. From material procurement to after-sale transportation services, the logistics is crucial [5]. As far as Yunnan is concerned, the logistics system in Yunnan Province is far from perfect. Most of the logistics companie's business are single and the logistics service quality is not high. The logistics enterprises in Yunnan still have small, scattered, and weak problems on the whole, and the levels of intensive development are low. The information sharing plays an important role in the logistics industry. Good logistics facilities will save a lot of costs and expenses for the operation of the manufacturing industry, even the production of the manufacturing industry will go smoothly. At the same time, the function of the logistics industry in Yunnan Province is too monotonous, it only plays a role in simple transportation. That is, there are few third-party logistics companies, some comprehensive functions, such as coordinating operations with manufacturing companies, are still to be developed. The lack of logistics companies in the state is also a factor that affects the further expansion of the manufacturing industry. The lag in the logistics industry in Yunnan Province has become a major bottleneck in the development of the manufacturing industry.

\section{E. Weak independent innovation}

Technological innovation is a key factor in industrial upgrading. For Yunnan's manufacturing industry, the independent innovation capability is weak. In 2017, the technological R\&D investments in Yunnan's manufacturing industry were far greater than its innovation results. The technology investment funds accounted for $8.65 \%$, but the product innovation rate was only around 3.9\%. Therefore, it can be seen that the input proportion of independent innovation in Yunnan Province is very low, the capacity for innovative products is weak, and the lower input and ability of technological innovation have seriously constrained the transformation and upgrading of manufacturing in Yunnan Province [6]. In the economic growth, the scientific and technological progress in Yunnan Province contributes less to the development of manufacturing companies, the technological innovation output capacity is lower than the level of science and technology inputs. In other words, Yunnan Province do not provide corresponding policies and financial support for the corresponding independent innovation, which makes the independent innovation of Yunnan's manufacturing industry stagnant, it lead to a huge challenge for the future development of the manufacturing industry. 
IV. SUGGESTIONS FOR PROMOTING THE TRANSFORMATION AND UPGRADING OF MANUFACTURING INDUSTRY IN YUNNAN

\section{A. The government leads to promote the transformation of the manufacturing structure from singleness to diversification}

For the manufacturing, the structural adjustment is an important means to promote its development. Yunnan Province should be led by the government to promote the transformation of the manufacturing structure from singleness to diversification. In the process of modern industrialization in Yunnan Province, more than $90 \%$ of manufacturing companies have not formed the ability to upgrade themselves. Under such circumstances, it is necessary for the government to provide a strong fulcrum to lead the promotion of the diversified development of the manufacturing structure. In view of the fact that the concentration of manufacturing industry in Yunnan Province is relatively low and decentralized, before the clustering of manufacturing industries has not formed, the development of manufacturing clusters requires further policy support from the Yunnan provincial government. Therefore, from the aspects of the professional market system innovation, the governments at all levels should increase the joint degree between the manufacturing products and the big market, promote the improvement of the manufacturing structure. Furthermore, the government should organize the establishment of an information sharing platform and integrate manufacturing information resources, allow a single manufacturing industry to constantly improve its own business under the guidance of reasonable industrial policies, optimize production lines, eliminate backward production capacity.

\section{B. Accelerating the implementation of manufacturing cluster development strategy}

The examples of multi-industry clusters prove that the expansion of market size is mainly achieved through industrial clusters. The industrial agglomeration is crucial to the development of the company, especially in the highly concentrated manufacturing industry. Therefore, accelerating the implementation of industrial agglomeration is crucial for the development of the manufacturing industry in Yunnan Province. At present, Yunnan's manufacturing industry is relatively fragmented, has developed slowly, and has not obtained the corresponding advantages of agglomeration. Therefore, Yunnan Province should speed up the implementation of the manufacturing cluster development strategy, based on the actual development of the province's manufacturing industry. Specifically, the role of the government is a guide and supporters, the government determines the strategic positioning of the manufacturing enterprise cluster, formulates detailed planning rules and related policy support for the enterprise cluster, seriously selects enterprises that possess core competitiveness and comparative advantages, integrates the market, establishs regional network platforms of manufacturing enterprise clusters through modern information technology. In the implementation process, it avoids to use the park as a cluster, adopts the principle of differentiation to avoid vicious competition among enterprises. It forms a manufacturing cluster industrial chain led by the government with social supervision and self-discipline.

\section{Establishing cooperative mechanism in universities and training professionals}

The purpose of higher education is to train talents in various fields that can adapt well to the economic development of modern society and have the ability to integrate and apply knowledge and practice. However, for Yunnan Province, due to the time lag of education and the lack of information, colleges and universities in Yunnan Province can not timely meet the demand for professional talents, which has caused the development of manufacturing industry to lag behind. Therefore, Yunnan Province should establish a university cooperation mechanism and train a large number of professional manufacturing talents to create a corresponding talent base for the development of Yunnan's manufacturing industry. Training the corresponding manufacturing personnel requires enterprises and universities to jointly develop students' abilities, and cultivate a large number of technical talents for the development of manufacturing in Yunnan Province. At the same time, it is necessary to adjust the educational structure and train a large number of technical talents to cope with the transformation and upgrading of the manufacturing industry in Yunnan Province. While the manufacturing industry employs various types of technology and management personnel for a long period of time, it can timely adjust the number of workers based the needs of its own production, reduce the cost of wages and workers' labor security.

\section{Increasing financial support and balancing the allocation of industrial financial resources}

The local governments at all levels in Yunnan Province should take the lead in establishing a guarantee fund to provide guarantees for the financing of manufacturing and guarantee the development of the manufacturing industry. At present, more than $90 \%$ of manufacturing enterprises in Yunnan Province are actively seeking to increase investment, but suffer from the lack of collateral and cannot obtain credit funds from local or foreign banks and other formal financial institutions to promote their development. Therefore, Yunnan Province should increase financial support for relevant manufacturing companies and balance the allocation of industrial financial resources. Through the establishment of financial support mechanisms for the development of the manufacturing industry at provincial and municipal levels, governments should encourage to set up special guarantee funds for the manufacturing industry in all counties (cities, districts) led by local governments. In addition, Yunnan Province should make good use of various innovative financial instruments to support the upgrading of the manufacturing industry and promote the transformation and growth of the manufacturing industry in Yunnan Province. At present, Yunnan's financial institutions are incompatible with the characteristics of manufacturing industries in terms of credit management models and financial innovation capabilities. Therefore, the financial institutions should innovate the service system for manufacturing enterprises, strengthen financial support for scientific and technological 
innovation and upgrading of manufacturing enterprises in Yunnan Province, so as to balance the resource allocation of Yunnan's manufacturing industry.

\section{E. Increasing the construction of logistics infrastructure}

Because the development of manufacturing industry requires the coordination of strong logistics infrastructure, the Yunnan Provincial Government should actively promote the joint development model of the manufacturing and logistics industries, promote the harmonious development of the manufacturing and logistics industries [7]. On the one hand, this development model can allow the industrial chain of the manufacturing industry to better integrate with the resources of the logistics industry and change the single function of the previous logistics industry. On the other hand, information sharing can be achieved and information asymmetry can be reduced, which allows manufacturing and logistics to generate greater economic added value. At present, the number of logistics enterprises in Yunnan is far from the rapid development of the needs of the manufacturing industry, the Yunnan Provincial Government should set up special funds to support the construction of logistics infrastructure, continue to strengthen the merger of small logistics companies, and guide logistics companies to become bigger and stronger. Establishing a set of logistics industry level goals with international industry, under the development policy of One Belt One Road, Yunnan's trading industry will be greatly improved, the logistics industry and manufacturing industry will have great opportunities for development.

\section{F. Actively exploring new technological innovation models}

The technological innovation requires the support of national policies, such as improving the financial policies, promoting the financing diversification, improving the legal systems, strengthening the protection of technological innovations, and giving the financial tax subsidies for innovative projects [8]. The road of the technological innovation in small and medium-sized manufacturing industry requires both internal and external conditions. On the one hand, the rising awareness of innovation in corporate organizations requires the internal hard conditions for talents, facilities, and management. On the other hand, it requires good policy environment, economic environment, and social development, which create an atmosphere of respecting science and technology and pursuing innovation. Once the technological innovation is successful, it can bring greater economic added value. Firstly, the manufacturing cost is a substantial reduction. On the basis of achieving scale production, the single manufacturing cost will decrease with the increase in the number of production. At the same time, the technological innovation can also break through the previous production technology and quality, achieve lean production, make products quality higher, and reduce the scrap rates, which achieves a resource-saving and environment-friendly manufacturing development model.

\section{CONCLUSION}

The research results show that Yunnan's manufacturing industry has significant economic benefits, the industrial enterprises are rapidly developing, the industrial structure adjustment is tending to optimize, and a new industrialization system is being built. However, there is a big gap of the comprehensive competitiveness in the manufacturing industry between Yunnan and developed provinces. There are many factors that restrict the transformation and upgrading of manufacturing in Yunnan Province. These restrictive factors mainly include: traditional path dependence, insufficient reserve of professional talents, inadequate financial assistance, imperfect logistics system, and weak independent innovation capability. In view of the existing restrictive factors, we put forward the suggestions to promote the transformation and upgrading of Yunnan manufacturing industry, so as to early realize the rapid and efficient development of Yunnan manufacturing industry.

\section{REFERENCES}

[1] Qizi Zhang, Lei Li. Manufacturing Transformation and Regional Economic Growth [J]. Economic Management Research, 2017, 38(02): 97-111.

[2] Xiaoyong Huang, Wei Liu, Fei Wen. Analysis of the dynamic mechanism of industrial upgrading in the western region: Taking Chongqing as an example [J]. Management Modernization, 2012, (05):47-49.

[3] Zhiyuan Zhang, Zhaoyou Li. The dynamic mechanism and strategic trend of the transformation and upgrading of China's manufacturing industry in the new normal state $[\mathrm{J}]$. Exploration of economic issues, 2015, (06): 144-149.

[4] Xiangjun Tang, Baoping Ren. Limited supply of labor, demographic transition and sustainability of China's economic growth [J]. Nankai Economic Research, 2010, (5): 84-94.

[5] Shaojun Zhang, Zhibiao Liu. Industrial transfer of the global value chain model - motivation, influence and inspiration for China's industrial upgrading and regional coordinated development $[\mathrm{J}]$. Chinese Industrial Economy, 2009, (11): 5-15.

[6] Zicheng Li, Wenni Wang. Discussion on the Development of Exportoriented Processing Industry in Yunnan [J]. Market Modernization, 2016, (30): 142-145.

[7] Zhigang Chen, Junsheng Ma. The analysis of the industry association between manufacturing industry and logistics industry in Yunnan [J]. Logistics Technology, 2011, 30(11): 79-82.

[8] Xun Meng. Five major areas of force to break through the manufacturing industry in Yunnan "sword" $[\mathrm{N}]$. Yunnan Economic Daily, 2016-07-28 (A02). 